\title{
O camponês e o agricultor nas representações sociais de estudantes universitários
}

\author{
Denis Giovani Monteiro Naiff ${ }^{1}$ - Universidade Federal Rural do Rio de Janeiro, Rio de Janeiro, Brasil \\ Rosa Cristina Monteiro - Universidade Federal Rural do Rio de Janeiro, Rio de Janeiro, Brasil \\ Luciene Alves Miguez, Naiff - Universidade Federal Rural do Rio de Janeiro, Rio de Janeiro, Brasil
}

\begin{abstract}
Resumo
O debate contemporâneo sobre o universo agrário tem suscitado uma questão importante: como se estruturam as identidades de sujeitos/atores sociais envolvidos com a atividade agrícola no bojo de processos socioculturais que implicam transformações de pensamento e hábito de indivíduos e instituições? Este estudo teve como objetivo identificar e comparar as representações sociais que 400 alunos de uma universidade federal rural possuem sobre as identidades de camponeses e agricultores. Foi utilizada uma tarefa de evocação livre com os termos indutores "agricultor" e "camponês" para obtenção dos dados. Os resultados apontam para o fato de que os camponeses são representados pelos estudantes como os sujeitos arcaicos, deslocados historicamente e excluídos das formas de produção econômicas vigentes no campo, enquanto os agricultores são compartilhados pelos alunos como modernos agricultores familiares, muito mais atraentes às novas gerações, produtores de riquezas e de desenvolvimento no campo, além de menos geradores de tensão.

Palavras-chave: representações sociais; camponês; agricultor.
\end{abstract}

\section{Social representations of college students on cottagers and rural workers}

\begin{abstract}
The current debate on rural issues has raised an important question: how social identities of individuals envolved with agricultural activities are built, taking into consideration that these identities imply in changes of thoughts and habits of individuals and institutions? The present study identified and compared social representations of 400 students from a rural university on cottagers and agricultural workers. The activities envolved the free usage of terms such as "rural worker" and "cottagers" to analyze what there reponses would be. The results showed that the student's perceptions of cottagers are related to pre-conceived notions such as archaic and excluded from current types of economical production while agricultural worker is seen as modern and more appealing to younger generations and also least involved in local conflicts and tensions.
\end{abstract}

Key-words: social representations; cottagers; agricultural worker.

\section{Introdução}

O debate contemporâneo sobre o universo agrário tem suscitado uma questão importante: Como se estruturam as identidades de sujeitos/atores sociais envolvidos com a atividade agrícola no bojo de processos socioculturais que implicam transformações de pensamento e hábito de indivíduos e instituições? Dois atores têm estado presentes no centro deste debate: o camponês, estruturado mediante a organização do trabalho, da vida política e social com instrumentos e valores morais destoantes dos padrões capitalistas; e o agricultor, cuja identidade se aglutinaria na organização do trabalho com novas tecnologias, mudanças de hábitos, de expressão cultural e de sua imersão na lógica econômica com a constante produção de mercadorias (Balsan, 2006; Carneiro, 1998; Fernandez, 2001; Marques \& Bleil, 2000; Moreira, 2003). A dimensão camponesa, segundo Felício (2006a), estaria estruturada ao redor de dois paradigmas, a saber: a) do capitalismo agrário que advoga que o único futuro possível ao campesinato está na metamorfose do camponês em agricultor familiar, e b) da questão agrária que entende que a luta pela terra e pela reforma agrária é a forma privilegiada de criação e recriação da identidade camponesa. Em outras palavras, o camponês é aquele que luta pela terra e na falta de conflito agrário perde sua razão de existência.

Para muitos autores o termo camponês não daria mais conta de traduzir o modo de vida dos pequenos trabalhadores agrícolas na sociedade capitalista moderna, que elege o mercado como o principal lócus de sociabilidade de seus indivíduos (Abramovay, 1992; Gehlen, 2004; Lamarche, 1993). Assim, a identidade social camponesa teria se tornado inoperante, e esse agente social se transmudado em agricultores no caldo da modernidade capitalista, fato já preconizado nas obras seminais de Lênin (1899/1980, 1918/1985), que, ao discutir o desenvolvimento do capitalismo na Rússia e nos Estados Unidos da América, explicava o processo de exploração e destruição do campesinato e a eliminação do camponês como fruto do avanço

${ }^{1}$ Endereço para correspondência:

Rua Conselheiro Olegário 34/103 - Maracanã - 20271-090 - Rio de Janeiro-RJ, Brasil

Tel - Fax: (21) 2234-72-82

E-mail: dnaiff@oi.com.br; dnaiff@ufrrj.br 
capitalista. Dessa forma, estaríamos assistindo à morte do camponês enquanto identidade social com poder explicativo no universo agrário (Fernandez, 2001; Pietrafesa, 2000;).

Entretanto, o camponês enquanto ator social busca formas de resistência em entidades classistas atuantes na mediação dos conflitos agrários, como o Movimento dos Sem-Terra (MST) e a Via Campesina na realidade brasileira, tornando-se muitas vezes um incômodo para os que advogam uma ruralidade "moderna" (Felício 2006b; Fernandez, 2000; Gaiger, 1999;). Segundo Fernandez (2004),

no Brasil, nos últimos 20 anos, não foi o mercado que possibilitou a recriação do campesinato, mas sim a luta política desenvolvida por meio das ocupações de terra que se tornou a principal forma de acesso à terra (p. 27)

As universidades rurais brasileiras - pela sua própria vocação - têm estado na vanguarda da busca de sentidos para esse universo rural que se estrutura, baseado em novas relações intergrupais e configurações identitárias. Neste contexto, entendemos que as representações sociais, por se apresentarem como uma modalidade de conhecimento construída e compartilhada no ambiente social e que têm como um dos objetivos a orientação de práticas e comportamentos (Abric, 2001a), podem proporcionar um maior entendimento dos elementos constituintes das categorias de camponês e agricultor presentes nos seus alunos universitários, muitos deles futuros atores sociais do universo rural brasileiro, pois

as pesquisas sobre a construção de categorias sociais não têm ignorado o papel que as representações sociais desempenham na sua produção, assim como na sua saliência em contextos sociais específicos. (Vala, 1997, p. 8)

É no universo sociocultural que estão e são continuamente produzidas as representações sociais. Se quisermos compreender por que uma pessoa se comporta de um jeito e não de outro devemos ver as relações sociais embutidas em seu cotidiano. Nossas reações em relação a outras pessoas e objetos sociais estão em grande parte mediadas pela percepção e pelas representações sociais que fazemos dela (Moscovici, 1988; 2003).

O conceito de representação social designa uma forma específica de conhecimento, o saber do senso comum, cujos conteúdos manifestam a operação de processos generativos e funcionais socialmente marcados. Mais amplamente, designa uma forma de pensamento social. Uma definição muito bem aceita dentro do campo e que resume suas principais características é dada por Jodelet (2001, p. 22), na qual as representações sociais são

uma forma de conhecimento, socialmente elaborada e partilhada, com um objetivo prático, e que contribui para a construção de uma realidade comum a um conjunto social.

Falar em representações sociais implica em considerá-las como emergentes na dimensão simbólica da vida social, pois servem para agir sobre o mundo e sobre os outros. O objetivo principal de lançarmos mão de representações sociais é buscar compreender o mundo a nossa volta (Moscovici, 1987; 1992). Os processos responsáveis pela formação das representações sociais são a objetivação e a ancoragem. Isso significa dizer que objetivamos o desconhecido dando-lhe forma, tornando-o quase palpável, e o ancoramos em nosso próprio sistema de referência preexistente, utilizando essa estrutura como guia de nossas ações. No entanto, o que se caracteriza como desconhecido ou, usando o termo moscoviciano, "não-familiar", deve estar associado a um grau suficientemente grande de relevância para um determinado grupo, para que então, possa gerar as conversações e seu consequente domínio (Vala, 1993; Wagner, 1998).

As representações sociais possuem, segundo Abric (2001b), uma organização significante, isto é, não são apenas reproduções da realidade, estão imersas em um contexto mais imediato e outro mais global. A formação de representações sociais, portanto, agrega duas principais características de acordo com o que vimos até aqui: em primeiro lugar a premissa de que as representações sociais têm o objetivo de transformar o não-familiar em familiar, e em segundo lugar é uma modalidade, segundo Moscovici (1961/1979a; 1984), que tem por função direcionar o comportamento e a comunicação.

Este artigo teve como objetivo encontrar e comparar as representações sociais que estudantes da Universidade Federal Rural do Rio de Janeiro (UFRRJ) possuem sobre as figuras do agricultor e do camponês, identificando as similitudes e diferenças entre os conceitos, muitas vezes entendidos como sinônimos no universo do senso comum.

\section{Método}

Este estudo foi aprovado pelo comitê de ética da Universidade Federal Rural do Rio de Janeiro, conforme a resolução CNS/MS, $n^{\circ}$ 196/96. 
Participaram da pesquisa 400 estudantes da Universidade Federal Rural do Rio de Janeiro UFRRJ, sendo 200 alunos matriculados em cursos classificados no Conselho Nacional de Desenvolvimento Cientifico e Tecnológico (CNPq) como pertencentes à área de ciências agrárias - como agronomia, veterinária, zootecnia, etc. -, e 200 alunos matriculados nos outros cursos de graduação oferecidos pela instituição, como as licenciaturas em física, quimica, biologia, matemática, história, etc.

Os sujeitos foram submetidos a uma tarefa de evocação livre, na qual lhes foi solicitado que expressassem espontaneamente cinco palavras ou expressões que lhes viessem imediatamente à lembrança quando apresentávamos os termos indutores "camponês" e "agricultor". As tarefas de evocação foram distribuídas de forma excludente. Cada sujeito que participou da tarefa de evocação sobre o camponês não participou da evocação com o termo indutor agricultor, pois os termos foram considerados semanticamente aproximados na linguagem cotidiana, evitando dessa forma que a primeira evocação gerasse no sujeito um possível efeito residual que influenciaria a evocação ao segundo termo, fenômeno conhecido na literatura como efeito carry-over, uma possível medida a ser tomada para evitar efeitos carry-over é a inclusão de um período de wash-out entre a apresentação de termos indutores similares semanticamente para os mesmos sujeitos, de modo que todo efeito residual do estímulo anterior seja eliminado. Dessa forma, tivemos ao final cada termo evocado por 100 sujeitos diferentes de cada subgrupo.

Em uma segunda etapa foi pedido aos estudantes que hierarquizassem por grau de importância as palavras ou expressões evocadas anteriormente. Essa técnica combinada aproveita o material bruto nascido da associação livre e o organiza cognitivamente, permitindo uma reavaliação da ordem de evocação, de acordo com indicação de Abric (2003), que advoga pela substituição do "rang de aparição" pelo "rang de importância" como produto final da coleta de dados.

As questões de evocação livre foram submetidas a uma análise de conteúdo com auxilio do programa de computador denominado EVOC $2003 \AA$ (Ensemble de programmes permettant l'analyse des evocations), cuja lógica procura combinar a frequência com que as palavras e expressões são emitidas pelos sujeitos com a ordem em que cada sujeito as evoca, permitindo apreender quais os elementos das representações sociais são presentes de forma mais central na produção discursiva dos sujeitos (Oliveira, Marques, Gomes \& Teixeira, 2005).

A tabela 1 apresenta uma esquematização da distribuição dos resultados gerados pela técnica da evocação livre. O cruzamento da freqüência média das evocações com a ordem média em que foram evocadas gera quatro quadrantes, pelos quais os elementos evocados se distribuem. A técnica advoga que no quadrante superior esquerdo se alocariam os possíveis elementos centrais e no quadrante inferior direito estariam os elementos claramente periféricos nessa representação. A lógica subjacente à técnica empregada é que os elementos que ao mesmo tempo tenham sido mais freqüentes e mais prontamente evocados teriam maior probabilidade de pertencerem ao núcleo central da representação social estudada (Vergès, 1994; 2005).

No $2^{\circ}$ quadrante encontramos a $1^{\mathrm{a}}$ periferia composta pelos elementos periféricos mais importantes da representação, possuidores de freqüência elevada. $O$ terceiro quadrante seria composto pelos elementos de contraste, que foram considerados importantes pelos sujeitos apesar de baixa frequência. Abric (2003) considera que este quadrante pode tanto "revelar a existência de um subgrupo minoritário portador de uma representação diferente" (p. 64), como ser apenas composto de elementos complementares da $1^{\text {a }}$ periferia. No $4^{\circ}$ quadrante, teríamos os elementos claramente periféricos da representação.

Tabela 1 - Representação esquemática da distribuição das cognições das representações sociais no modelo de evocação livre

Ordem média de evocação

\begin{tabular}{|c|c|c|}
\hline \multirow{2}{*}{ Frequência média } & $\begin{array}{l}1^{\circ} \text { quadrante } \\
\text { Elementos do Núcleo Central } \\
\text { prontamente evocados }+ \text { alta frequência }\end{array}$ & $\begin{array}{l}2^{\circ} \text { quadrante } \\
\text { Elementos da } 1^{a} \text { periferia } \\
\text { tardiamente evocados }+ \text { alta frequência }\end{array}$ \\
\hline & $\begin{array}{l}3^{\circ} \text { quadrante } \\
\text { Elementos de contraste } \\
\text { prontamente evocados }+ \text { baixa frequência }\end{array}$ & $\begin{array}{l}4^{\circ} \text { quadrante } \\
\text { Elementos da } 2^{\mathrm{a}} \text { periferia } \\
\text { tardiamente evocados }+ \text { baixa frequência }\end{array}$ \\
\hline
\end{tabular}




\section{Resultados e discussão:}

As tabelas 2 e 3 apresentam a distribuição das evocações para a figura do camponês. Os dados apontam para um provável núcleo central da representação social entre os estudantes de cursos de não-agrárias e de ciências agrárias, estruturado ao redor de uma figura ideologizada, configurada por um trabalhador do campo ligado à terra $\mathrm{e}$ geograficamente localizado numa zonarural. Os estudantes de não-agrárias localizam o camponês como um ator social provavelmente ainda pertencente a modos similares de produção aos modelos descritos como representantes do período feudal, enquanto os alunos de agrárias, mais familiarizados com a questão do campo brasileiro, ainda o identificam presente na dimensão agrária contemporânea. Os dois grupos comungam de visões similares do camponês na primeira periferia da provável estrutura da representação, formada por uma figura identificada pela pobreza e simplicidade na condução da vida. Como diferenças, vale destacar a dimensão ideológica presente nas representações dos camponeses objetivados por trabalhadores explorados economicamente na visão dos alunos de não-agrárias; enquanto os estudantes de ciências agrárias comungam de uma visão idílica do camponês como sujeito social ligado às dimensões familiares e aos valores do campo. Merece destaque a aparente ausência da dimensão conflitual atrelada à figura camponesa nas representações das duas amostras. Como exemplo, os resultados presentes nas tabelas 2 e 3 não apontam referências explicitas à reformaagrária - bandeira ideológica identitária desse grupo social - ou ao Movimento dos Sem-Terra.

Tabela 2 - Representação do camponês em estudantes de cursos não de agrárias

\begin{tabular}{|c|c|c|c|c|c|}
\hline \multicolumn{6}{|c|}{$<2,9$ ordem média de evocação $\geq 2,9$} \\
\hline Campo & 56 & 1,67 & Plantação & 19 & 3,47 \\
\hline Trabalhador & 36 & 2,33 & Pobreza & 16 & 3,50 \\
\hline Feudalismo & 17 & 2,88 & Enxada & 15 & 3,40 \\
\hline Zona-rural & 16 & 2,06 & Simples & 13 & 3,08 \\
\hline Terra & 14 & 2,21 & Fazenda & 14 & 2,92 \\
\hline & & & \multicolumn{3}{|c|}{ Frequência $\geq 13$} \\
\hline \multicolumn{6}{|c|}{ Frequência $<13$} \\
\hline Agricultura & 8 & 2,87 & Humilde & 11 & 3,91 \\
\hline Árvore & 7 & 2,43 & Animais & 10 & 3,40 \\
\hline Mato & 7 & 1,86 & Casa de madeira & 9 & 3,56 \\
\hline Flores & 6 & 2,00 & Colheita & 7 & 4,43 \\
\hline \multirow[t]{3}{*}{ Homem do campo } & 6 & 2,50 & Interior & 6 & 3,67 \\
\hline & & & História & 5 & 3,00 \\
\hline & & & Tranqüilidade & 5 & 3,60 \\
\hline
\end{tabular}

Tabela 3 - Representação do camponês em estudantes de cursos de ciências agrárias

\begin{tabular}{|c|c|c|c|c|c|}
\hline \multicolumn{6}{|c|}{$<2,9$ ordem média de evocação $\geq 2,9$} \\
\hline Trabalhador & 44 & 2,54 & Pobreza & 37 & 2,91 \\
\hline Campo & 34 & 1,44 & Simples & 16 & 2,94 \\
\hline Agricultura & 26 & 2,62 & Família & 15 & 3,93 \\
\hline Zona-rural & 17 & 1,88 & & & \\
\hline Frequência $<15$ & & & Frequên & & \\
\hline Plantação & 10 & 2,70 & Terra & 14 & 3,21 \\
\hline Humilde & 9 & 2,78 & Animais & 11 & 3,27 \\
\hline Produção & 8 & 2,88 & Fazenda & 5 & 3,60 \\
\hline Feudalismo & 7 & 2,29 & & & \\
\hline Enxada & 4 & 2,75 & & & \\
\hline Mato & 4 & 2,75 & & & \\
\hline
\end{tabular}

Em relação às representações sociais do agricultor (tabelas 4 e 5), os resultados apontam que as duas amostras comungam a noção de um agricultor como sujeitos trabalhadores em plantações de gêneros alimentícios. Contudo, para os estudantes de ciências agrárias, o agricultor na modernidade se 
estrutura em torno de uma identidade social relacionada ao capitalismo nas suas macro-dimensões rurais, ou seja, um produtor de mercadorias plenamente integrado ao agronegócio; por outro lado, esta dimensão aparece apenas de forma periférica na estrutura das representações sociais dos alunos de cursos de não-agrárias. Valem também destacar como elementos periféricos a presença de dimensões ideológicas relacionadas à figura do camponês na representação social do agricultor nos estudantes de cursos de agrárias, como a reformaagrária, a pobreza e a humildade, refletindo, ainda que de forma periférica, a similitude semântica ainda presente em relação aos conceitos aqui estudados (agricultor e camponês).

Tabela 4 - Representação do agricultor em estudantes de cursos não-agrários

\begin{tabular}{lccccc}
\hline \multicolumn{5}{c}{$<3,0$ ordem média de evocação $\geq 3,0$} \\
\hline Plantações & 99 & 2,58 & Alimentos & 25 & 3,32 \\
Terra & 47 & 2,30 & & & \\
Trabalhador & 26 & 3,00 & & & \\
& & & Frequência $\geq 21$ & & \\
Frequência $<21$ & 16 & 2,88 & Campo & 15 & 3,20 \\
Enxada & 15 & 2,40 & Fazenda & 15 & 3,20 \\
Produtor & 9 & 2,67 & Adubo & 12 & 3,67 \\
Agronegócio & 9 & 2,33 & Semente & 12 & 3,25 \\
Mato & & & Zona-rural & 8 & 3,63 \\
& & & Trator & 7 & 3,71 \\
& & & Animais & 6 & 3,67 \\
\hline
\end{tabular}

Tabela 5 - Representação do agricultor em estudantes de cursos de ciências agrárias

\begin{tabular}{ccccc}
\hline & \multicolumn{3}{c}{$<3,0$} & ordem média de evocação $\geq 3,0$ \\
\hline Plantações & 52 & 2,79 & Alimentos & \\
Terra & 48 & 1,82 & & \\
Produtor & 31 & 2,39 & & \\
Trabalhador & 26 & 2,84 & \\
Agronegócio & 19 & 2,98 & \\
Agricultura & 18 & 2,72 &
\end{tabular}

Frequência $\geq 17$

Frequência $<17$

$\begin{array}{ccc}\text { Campo } & 13 & 1,77 \\ \text { Reforma-agrária } & 12 & 2,84 \\ \text { Família } & 7 & 2,85 \\ \text { Enxada } & 6 & 2,00\end{array}$

Zona-rural
Agricultura-familiar
Pobreza
Humilde
Trator

$14 \quad 3,29$

$9 \quad 4,00$

$9 \quad 3,78$

$6 \quad 3,83$

$6 \quad 3,17$

\section{Considerações finais}

Os dados apontam para o fato de que o camponês é representado na atualidade pelos estudantes da UFRRJ como um excluído das formas de produção econômicas vigentes no campo - fato exemplificado na atuação política de suas entidades classistas no Brasil (o Movimento dos Sem-Terra e a Via Campesina, por exemplo), que possuem projetos institucionais de resgate em seus integrantes da identidade camponesa (Felício, 2006b) - fato que reforça a noção de que os termos que definem uma agricultura camponesa têm de ser discutidos não baseados em uma economia de mercado, como normalmente é feito, mas buscando-se sua definição tomando por base características específicas no interior dessas unidades, algo que se situa mais na esfera da autonomia da produção do que na dependência da circulação (Schneider, 2003; Silva, 1999; Velteimeyer, 1997). Unidades que se diferenciam, no tempo e no espaço, de leis gerais de relações de produção determinantes ou globais, muitas vezes como produtos antitéticos do desenvolvimento geral da sociedade (Oliveira, 2001).

Contrapondo-se ao camponês arcaico e deslocado historicamente, o capitalismo apresenta a sua transmudação em moderno agricultor familiar, muito mais atraente às novas gerações enquanto 
agente produtor de riquezas e de desenvolvimento no campo, e também menos gerador de tensões (Abramovay, 1992). A análise dos resultados das representações sociais do agricultor já aponta para essa nova configuração compartilhada principalmente pelos alunos de ciências agrícolas, futuros atores sociais da questão agrária brasileira, e sujei-

tos mais próximos das informações produzidas no universo reificado sobre a temática aludida.

Assim, torna-se importante aprofundar a investigação nas identidades rurais, buscando compreender, por exemplo, como os que ainda se identificam como camponeses estão vivenciando este momento histórico, principalmente pelas estratégias de influências minoritárias (Moscovici, 1979b; Moscovici, Mugny \& Pérez, 1991) utilizadas como resistência às tentativas de aniquilamento identitário em curso.

\section{Referências}

Abramovay, R. (1992). Paradigmas do capitalismo agrário em questão. São Paulo, SP: HUCITEC.

Abric, J.-C. (2001a). Prácticas sociales, representaciones sociales. Em J.-C. Abric (Ed.). Prácticas sociales y representaciones (pp. 195-214). México D. F.: Coyoacán.

Abric, J.-C. (2001b). Las representaciones sociales: aspectos teóricos. Em J.-C. Abric (Ed.). Prácticas sociales y representaciones (pp. 11-32). México D. F.: Coyoacán.

Abric, J.-C. (2003). La recherche du noyau central et la zone muette des représentations sociales. Em J.-C. Abric (Ed.). Méthodes d'étude des représentations sociales (pp. 59-80). Paris: Érès.

Balsan, C. (2006). Impactos decorrentes da modernização da agricultura brasileira. CampoTerritório: Revista de Geografia Agrária, 1(2), 123151.

Carneiro, M. J. (1998). Ruralidade: novas identidades em construção. Estudos: Sociedade e Agricultura, 11, 53-75.

Felício, M. J. (2006a). Os camponeses e os agricultores familiares: paradigmas em questão. Geografia, 15(1), 205-219.

Felício, M. J. (2006b). A conflitualidade dos paradigmas da questão agrária e do capitalismo agrário a partir dos conceitos de agricultor familiar e camponês. Campo-Território: Revista de Geográfia Agrária, 1(2), 14-30.

Fernadez, B. M. (2000). A formação do MST no Brasil. Petrópolis, RJ: Vozes.
Fernandez, B. M. (2001). Questão agrária, pesquisa e MST. São Paulo, SP: Cortez.

Fernandez, B. M. (2004). Espaços agrários de inclusão e exclusão social: novas configurações do campo brasileiro. Agrária, 1, 16-36.

Gaiger, L. I. (1999). As condições socioculturais do engajamento no MST. Estudos: Sociedade $e$ Agricultura, 13, 70-92.

Gehlen, I. (2004). Políticas públicas e desenvolvimento social rural. São Paulo em Perspectiva, 18 (2), 95-103.

Jodelet, D. (2001). Representações sociais: um domínio em expansão. Em D. Jodelet (Ed.). As representações sociais (pp. 17-44). Rio de Janeiro, RJ: Eduerj.

Lamarche, H. (1993). A agricultura familiar: uma realidade multiforme. Campinas, SP: Editora da Unicamp.

Lênin, V. I. (1899/1980). Capitalismo e agricultura nos Estados Unidos da América: novos dados sobre as leis de desenvolvimento do capitalismo na agricultura. São Paulo: Debates.

Lenin, V. I. (1918/1985). O desenvolvimento do capitalismo na Rússia. São Paulo: Nova Cultural.

Marques, P. E. M, \& Bleil, S. I. (2000). A identidade cultural desafia a globalização: o desabafo dos agricultores franceses. Estudos: Sociedade e Agricultura, 15, 158-177.

Moreira, R. J. (2003). Cultura, política e o mundo rural na contemporaneidade. Estudos: Sociedade e Agricultura, 20, 113-143.

Moscovici, S. (1961/1979a). El psicoanálisis, su imagen y su público. Buenos Aires: Huemul.

Moscovici, S. (1979b). Psicologie des minorités actives. Paris: Presses Universitaires de France.

Moscovici, S. (1984). The phenomenon of social representations. Em S. Moscovici (Ed.). Social representations (pp. 3-70). Cambridge: Cambridge University Press.

Moscovici, S. (1987). Answers and questions. Journal for the Theory of Social Behavior, 17(4), 513-529.

Moscovici, S. (1988). Notes towards a description of social representations. European Journal of Social Psychology, 18, 211-250.

Moscovici, S. (1992). La nouvelle pensée magique. Bulletin de Psychologie, 45(405), 301-324.

Moscovici, S. (2003). A história e a atualidade das representações sociais. Em S. Moscovici (Ed.). 
Representações sociais: investigações em psicologia social (pp. 167-214). Petrópolis, RJ: Vozes.

Moscovici, S., Mugny, G. \& Pérez, J. A. (1991). Influencia social inconsciente. Barcelona: Anthropos.

Oliveira, B. C. (2001). Tempo de travessia, tempo de recriação: os camponeses na caminhada. Estudos Avançados, 15(43), 61-77.

Oliveira, D. C., Marques, S. C., Gomes, A. M. T. \& Teixeira, M. A. T. V. (2005). Análise das evocações livres: uma técnica de análise estrutural das representações sociais. Em A. S. P. Moreira, B. V. Camargo, J. C. Jesuíno \& S. M. Nóbrega (Eds.). Perspectivas teórico-metodológicas em representações sociais (pp. 573-603). João Pessoa, PB: Editora da Universidade Federal da Paraíba.

Pietrafesa, J. P. (2000). Agricultura familiar e reprodução social. Sociedade e Cultura, $3(1 \& 2)$, 185-216.

Schneider, S. (2003). Teoria social, agricultura familiar e pluriatividade. Revista Brasileira de Ciências Sociais, 18(51), 99-121.

Silva, O. H. (1999). Agricultura familiar: diversidade e adaptabilidade. Revista de Sociologia e Política, 12, 161-167.

Tajfel, H. (1982). Grupos Humanos e Categorias Sociais (Vol. I e II). Lisboa: Livros Horizonte.

Vala, J. (1993). Representações sociais e psicologia do conhecimento quotidiano. Em J. Vala \& M. B.
Monteiro (Eds.). Psicologia Social (pp. 457-502). Lisboa: Fundação Calouste Gulbenkian.

Vala, J. (1997). Representações sociais e percepções intergrupais. Análise Social, 32(140), 7-29.

Velteimeyer, H. (1997). New social movement in Latin América: the dynamics of class and identity. Journal of Peasant Studies, 25(1), 139-169.

Vergès. P. (1994). Approche du noyau central: propriétés quantitatives et structurales. Em Ch. Guimelli (Ed.). Structures et transformations des représentations sociales (pp. 233-253). Lausane: Delachaux et Niestlé.

Vergès, P. (2005) A evocação do dinheiro: um método para a definição do núcleo central de uma representação. Em A. S. P. Moreira, B. V. Camargo, J. C. Jesuíno \& S. M. Nóbrega (Eds.). Perspectivas teórico-metodológicas em representacões sociais (pp. 471-488). João Pessoa, PB: Editora UFPB.

Wagner, W. (1998). Socio-gênese e características das representações sociais. Em A. S. P. Moreira \& D. C. de Oliveira (Eds.). Estudos interdisciplinares de representações sociais (pp.16-26). Goiânia, GO: AB.

Recebido em agosto de 2008 Reformulado em marco de 2009 Aprovado em marco de 2009

Sobre os autores:

Denis Giovani Monteiro Naiff é formado em psicologia pela Universidade de Brasília (UnB) e doutor em Psicologia Social pela Universidade do Estado do Rio de Janeiro (UERJ). Atualmente é professor adjunto do Departamento de psicologia da Universidade Federal Rural do Rio de Janeiro (UFRRJ) desenvolve pesquisas nas teorias das representações, memórias e identidades sociais.

Rosa Cristina Monteiro é formada em Psicologia pela Universidade Federal do Rio de Janeiro e doutora em Desenvolvimento, Agricultura e Sociedade pela Universidade Federal Rural do Rio de Janeiro (UFRRJ). Atualmente é professora associada do departamento de Psicologia da UFRRJ e professora do mestrado em Educação Agrícola da UFRRJ. Desenvolve pesquisas em psicologia ambiental, com ênfase nos temas: rural, ambiente, espaço, educação e natureza

Luciene Alves Miguez Naiff é formada em Psicologia pela Universidade Federal do Rio de Janeiro e doutora em Psicologia social pela Universidade do Estado do Rio de Janeiro (UERJ). Atualmente é professora titular do programa de Pós-Graduação Strito Sensu em Psicologia da Universidade Salgado de Oliveira e desenvolve pesquisas nas teorias das representações, memórias e identidades sociais, e suas articulações com a educação. 